\title{
IDIOPATHIC ARTERIAL CALCIFICATION IN INFANCY
}

\author{
BY \\ N. D. GOWER* and J. R. H. PINKERTON \\ From the Departments of Pathology, Edgware General Hospital, Middlesex, \\ and the Lincoln County Hospital
}

(RECEIVED FOR PUBLICATION JANUARY 16, 1963)

Arterial calcification has been known to occur in infancy since the early reports of Durante (1899) and Bryant and White (1901). In many instances arterial lesions have been associated with renal disease, hypervitaminosis-D or congenital anomalies of the heart and great vessels, but more rarely there has been no demonstrable primary disease. About 50 cases of this idiopathic type of arterial calcification in infancy have now been described and the published material has been comprehensively reviewed on several occasions (Field, 1946; Stryker, 1946; Moran and Becker, 1959). Nevertheless, our knowledge of the condition has not progressed beyond the descriptive stage, and hypotheses of its aetiology show no advance on those put forward by Stryker in 1946. From the standpoint of morbid anatomy and histology the cases described have been carbon-copies of each other and the various published photographs of the lesions could be interchanged without loss of context. Clinically, too, the cases have often been similar with sudden death as a usual occurrence.

Although idiopathic arterial calcification in infancy is not well known it is probably not as rare as the small number of recorded cases suggests. In addition to the two cases described here we know of two others that have not been recorded. We think, therefore, that this report is worth while, in the hope that wider recognition of the disease may lead to diagnosis during life and the institution of clinical and biochemical studies without which little further progress in understanding the disease is likely.

\section{Case Reports}

Case 1. F.D. was the sixth child of unrelated parents. His father and five sibs were all in good health, but his mother, aged 42 years, was found to be suffering from diabetes mellitus during the third trimester of pregnancy. On this account pregnancy was terminated at $\mathbf{3 7}$ weeks, the baby weighing $6 \mathrm{lb} .13 \mathrm{oz}$. $(3 \cdot 1 \mathrm{~kg}$.). He was breast

* Present address: Department of Pathology, Hallam Hospital, West Bromwich, Staffordshire. fed for a few days and subsequently received cows' milk with Truby King lime water and sugar mixture and, from the age of 5 weeks, one drachm of cod liver oil daily. Progress appeared to be perfectly normal until the age of 9 weeks, when, on April 27, 1958, he vomited after each feed. Next day he refused all feeds and during the afternoon suffered a fit of coughing which left him limp and pale, with cyanosed lips.

This condition persisted and the patient was admitted to Edgware General Hospital on April 29, 1958, after several screaming attacks had occurred during which he drew up his knees. Examination showed a pale, ill-looking baby in obvious distress and apparently in pain. The rectal temperature was $97 \cdot 8^{\circ} \mathrm{F}$. $\left(37 \cdot 1^{\circ} \mathrm{C}\right.$.), the heart rate was 160 per minute with a regular pulse of poor volume. The respiratory rate was 100 per minute. The lips and finger tips were deeply cyanosed and the extremities felt cold. Râles were heard all over the chest, but no other abnormality was discovered. A provisional diagnosis of pneumonia was made and oxygen and penicillin therapy instituted, but the baby's condition deteriorated and he died two hours after entering hospital.

Autopsy. The body was that of a normally-developed male infant weighing $9 \mathrm{lb} .10 \mathrm{oz}$. $(4 \cdot 37 \mathrm{~kg}$.). Apart from venous congestion no naked eye abnormality was discovered in any organ except the heart which was enlarged and weighed $52 \mathrm{~g}$. All its chambers were dilated and the wall of the right ventricle was thinned. The whole of the endocardium was thickened and glistening while the subendocardial muscle appeared unusually pale. The apex of the left ventricle was deep red in colour, suggesting a recent infarct. The most striking feature, however, was the great thickening and tortuosity of the coronary arteries which appeared as hard, beaded, pearly white cords (Fig. 1). On section the arterial walls were obviously thickened and partly calcified, with the lumina reduced to minute proportions, but the coronary ostia were macroscopically healthy.

Histology. The coronary arteries showed extensive calcification of the media with gross subintimal fibrosis (Fig. 2). The lesions were most severe in the proximal part of the vessels and milder, presumably younger, changes were found distally (cf. Fig. 3). The earliest change seen was deposition of calcium in the media immediately 


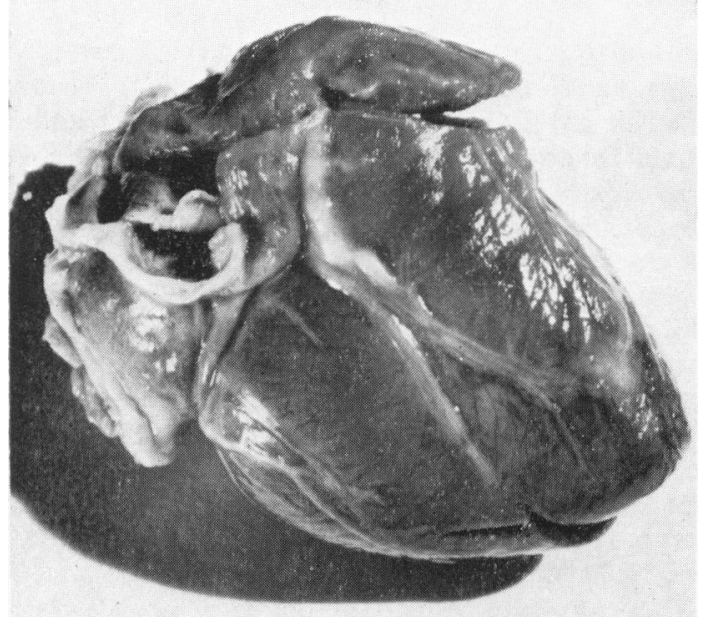

Fig. 1.-Case 1. Heart, showing thickening and beading of the coronary arteries.

adjacent to the internal elastic lamina. More advanced lesions showed gradual extension of calcification into the media, but even in very severely diseased vessels the elastica remained intact and there was little tendency for calcium to be laid down along its inner aspect, or for calcification of the subintimal tissue to occur, although both these features were occasionally observed. Sub-

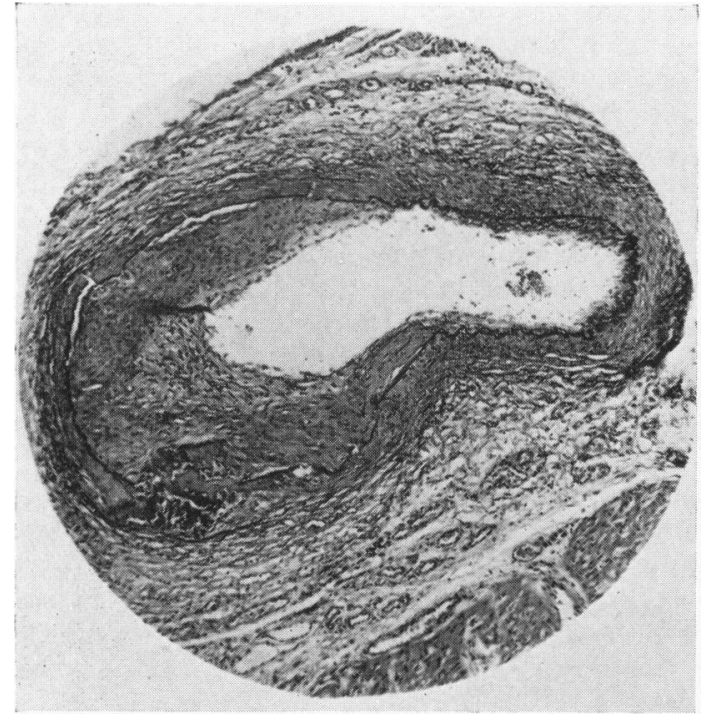

Fig. 3.-Case 2. Section of coronary artery showing an earlier lesion than Fig. 2. Subintimal fibrosis is less marked, but there is a foreign body reaction in the calcified media. (Haematoxylin and eosin $\times 55$.)

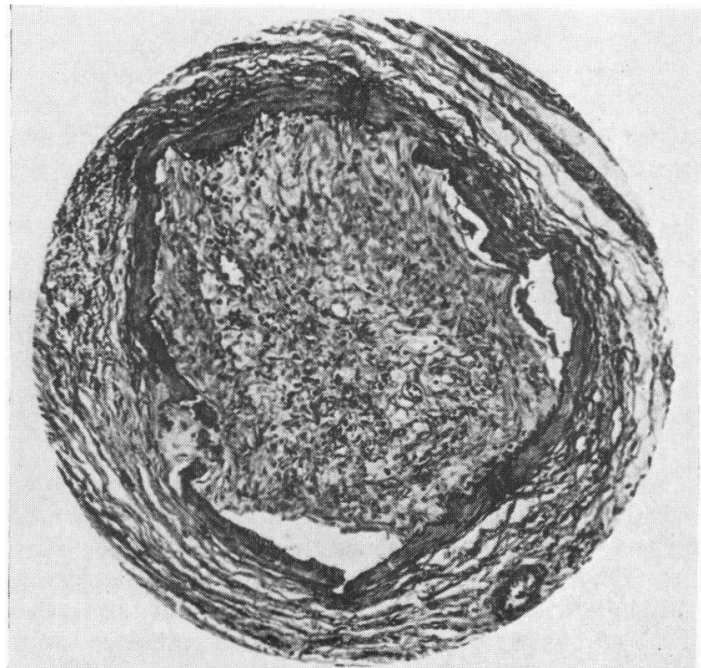

FIG. 2.-Section of coronary artery showing typical advanced lesion with medial calcification, preservation of the internal elastic lamina

and gross subintimal fibrosis. (Haematoxylin and eosin $\times 55$.)

intimal fibrosis was only seen in those parts of the vessels where medial calcification was advanced.

In the initial stages the young fibrous tissue was highly vascular, but in older lesions the capillary vessels had disappeared and the fibrous tissue showed mucoid change.

The aorta, pulmonary arteries and common carotid

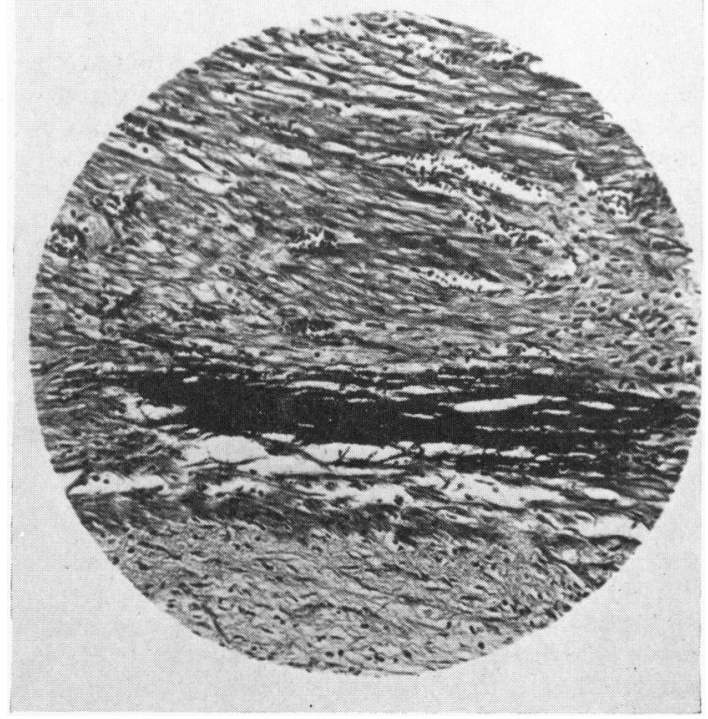

FIG. 4.-Case 1. Section of myocardium showing calcified myofibrils. (Haematoxylin and eosin $\times 110$.) 
arteries did not show calcification, although some swelling and basophilia of individual elastic fibres, or of small bundles of fibres, were seen both in the internal elastic lamina and in the media. Some of the small arteries in the mediastinal tissue removed with the heart were found to have changes identical with those in the coronary arteries.

In the heart itself there was extensive fine fibrosis of the subendocardial tissue. Capillary vessels throughout the myocardium were widely dilated and engorged, but nevertheless the heart muscle showed patchy necrosis, especially in the papillae and at the apex. Even very small necrotic patches showed calcification (Fig. 4), which in places was confined to individual muscle fibres.

Case 2. R.S. was the seventh child of healthy unrelated parents. One of his elder sisters was mentally retarded and had a choroidal defect with poor vision and nystagmus. There was radiological evidence of intracerebral calcification, but serological tests for syphilis and toxoplasmosis were negative. The other children were healthy.

The pregnancy was uneventful, the infant being born at term and weighing $6 \mathrm{lb} .12 \mathrm{oz} .(3 \cdot 1 \mathrm{~kg}$.). Progress on artificial feeding was normal until September 4, 1959 (aged 7 weeks) when he developed stridulous respiratory noises. Later in the day he refused his feeds but otherwise appeared well. A few hours later he collapsed quite suddenly, first becoming pale and then cyanosed. He was given aminophylline by the family doctor with considerable immediate improvement, and sent to St. George's Hospital, Lincoln; on arrival, however, his condition was critical with gasping respiration and faltering heart beat. Oxygen was given immediately but he died 10 minutes later.

Autopsy. The body was that of a normally-developed male infant. Vomit was present in the upper air passages and there was much frothy fluid in the bronchi and bronchioles. The pleural cavities each contained a large quantity of clear straw-coloured fluid. The lungs were partially collapsed and oedematous, but there was no obvious pneumonia.

The heart was a little enlarged, weighing $33 \mathrm{~g}$. with thickening of the walls of both ventricles. The myocardium was rather soft, and small whitish areas were scattered throughout the left ventricular wall. The coronary arteries were unduly prominent, glistening white, tortuous and raised above the surface of the pericardium. On section the vessels were seen to be thickened and their lumina greatly reduced.

Apart from congestion of the liver and spleen the other organs were macroscopically normal.

Histology. The changes in the coronary arteries, aorta and myocardium were virtually identical with those seen in Case 1, and do not therefore merit separate description. The lesions were not quite so advanced in Case 2, but in one or two places the medial calcification in the coronary arteries had provoked a foreign body giant cell reaction (Fig. 3).

\section{Discussion}

Idiopathic arterial calcification in infancy is a generalized disease, although coronary artery involvement is usually its most obvious feature. The coronary arteries were affected in 42 of the 44 cases reviewed by Moran and Becker (1959) who also noted the presence of widespread lesions in 28 cases where many arteries had been examined. Although examination of our cases was incomplete it is probable that both were genuine examples of the idiopathic generalized variety of infantile arterial calcification, as in neither case was there a history of excessive ingestion of vitamin $D$ or evidence of congenital anomaly of the heart or great vessels. The kidneys were macroscopically normal and in the first case a few small mediastinal vessels were found to be calcified on histological examination.

Clinically both cases were entirely typical. The sudden onset of acute respiratory symptoms has been the presenting feature in more than half the recorded cases, while a history of feeding difficulty or unusually good behaviour by the baby has been commoner than purely cardiac symptoms.

The possible aetiology of infantile arterial calcification has been discussed at length by Field (1946), Stryker (1946), Moran and Becker (1959) and Moran and Steiner (1962). Field suggested that the primary defect was in the intercellular substance of the media, but other writers have favoured the elastica as the primary site of calcification. Moran and Steiner investigated the possible interrelation of idiopathic arterial calcification, osteogenesis imperfecta and pseudoxanthoma elasticum. They regarded all these conditions as primarily disorders of elastic tissue, but were otherwise unable to suggest any direct relation between them.

A study of the published descriptions and photographs, and examination of our own material leads us to doubt the primary role of the elastica in infantile arterial calcification. Field described focal swelling of the intercellular substance of the media of the common carotid artery as the earliest change in her case, with deposition of calcium in the media adjacent to the internal elastic lamina as a slightly later change. Stryker found the earliest change to be basophilic granulation, presumably calcification, of the elastica, and several other writers (Moran and Becker, 1959; Sladden, 1952) have pointed out that the first calcium deposits are laid down in relation to the internal elastic lamina-sometimes on either side of it.

In our cases the changes in the muscular arteries have differed from those in the elastic vessels. In the latter (aorta, pulmonary arteries and proximal 


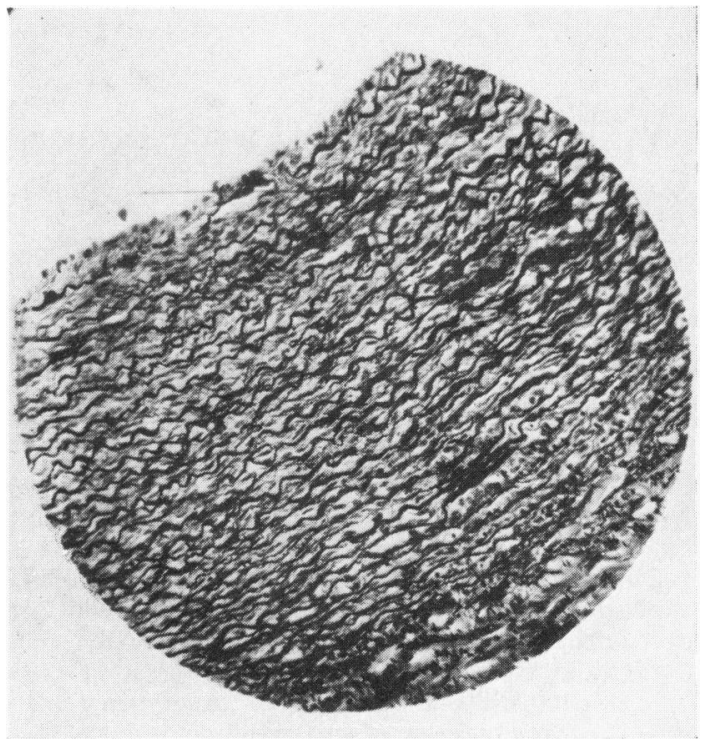

FIG. 5.-Case 1. Section of common carotid artery showing swelling and basophilia of elastic fibres. (Verhoeff's elastic stain $\times 110$.)

parts of the common carotid arteries) the first and only change we have seen is loss of outline with basophilia in individual elastic fibres (Fig. 5); we have been unable to demonstrate calcification in these lesions. In the muscular vessels there has been calcification of the media immediately adjacent to the internal elastic lamina; again there has been no demonstrable calcification of the elastica itself. Moreover, in these muscular vessels the elastica usually acts as a limiting membrane preventing the spread of calcium into the subintimal tissue, and even when calcium is deposited on both sides of the elastica the lamina itself is usually undamaged and retains its normal acidophil staining properties. It is therefore only in the major elastic vessels that we have seen any suggestion of primary abnormality of the elastic tissue. In contrast to this we have been impressed by the ease with which the ischaemic myocardium becomes calcified, and in some sections we have noticed necrosis and calcification of very small groups of myocardial fibrils occurring in a manner difficult to relate to impaired blood supply. In our cases calcification of muscle has been much more obvious than changes in elastic tissue.

Even though the aetiology of the condition remains unknown it is surprising that so little attention has been paid to the significance of subintimal fibrosis in the lesions. Ultimately it must surely be this fibrosis rather than the medial calcification, which produces the vascular occlusion responsible for the clinical features of the disease.

\section{Summary}

Two cases of idiopathic arterial calcification in babies, with predominant involvement of the coronary arteries, are described. The aetiology of the condition is unknown, but we suggest that calcification may occur primarily in muscle fibres rather than in the elastica and that the clinical features result from vascular occlusion dependent upon subintimal fibrosis rather than medial calcification.

We are most grateful to Dr. M. D. Baber and Dr. Trevor Wright, Consultant Paediatricians, for access to and the use of their clinical notes; to Dr. Riley, general practitioner, for his help; and to Miss P. M. Shaw for the photography.

\section{REFERENCES}

Bryant, J. H. and White, W. H. (1901). A case of calcification of the arteries and obliterative endarteritis, associated with hydro-

Durante, G. (1899). Athérome congénital de l'aorte et de l'artère pulmonaire. Bull. Soc. anat. Paris, 74, 97.

Field, M. H. (1946). Medial calcification of arteries of infants. Arch. Path., 42, 607.

Moran, J. J. and Becker, S. M. (1959). Idiopathic arterial calcification of infancy. Report of 2 cases occurring in siblings, and review of the literature. Amer. J. clin. Path., 31, 517. review of the literature. Amer. J clin. Path., 31, S17. in a 5 -year-old child. (ibid., 37,521 .

Sladden, R. A. (1952). Coronary arteriosclerosis and calcification in infancy. J. clin. Path., $5,175$.

Stryker, W. A. (1946). Arterial calcification in infancy with special reference to the coronary arteries. Amer. J. Path., 22, 1007. 